\title{
Impact factor 2012 for cardiovascular journals: true impact?
}

\author{
E. E. van der Wall
}

Published online: 13 August 2013

(C) The Author(s) 2013. This article is published with open access at Springerlink.com

In June 2013, the impact factors for the year 2012 were released (Thomson Reuters Journal Citation Reports ${ }^{\circledR}$ 2012, ISI Web of Knowledge). The impact factor is defined as the average number of citations received per paper divided by the published articles in a specific journal during the preceding 2 years [1-3]. The 2012 impact factor of the Netherlands Heart Journal (NHJ) was 1.411. The 2012 NHJ impact factor was calculated as follows: in 2012, the total number of citations to articles published in the years 2010 and 2011 was 207. The number of articles published in 2010 and 2011 was 146. As a result, the 2012 impact factor was 206 citations divided by 144 articles: 206/146 $=1.411$. The NHJ impact factor has therefore remained rather constant over the past 4 years: 1.392 in 2009, 1.447 in 2010, 1.438 in 2011, and 1.411 in 2012. Of course, we are striving to increase our impact factor over the forthcoming years (see the article by Tobias Opthof in the July/August edition of NHJ this year) [4].

From a European perspective, the impact factors of 2012 show the following interesting facts:

1) Out of a total number of 122 cardiovascular journals ( $\mathrm{sub}$ ject category Cardiac \& Cardiovascular Systems), the European Heart Journal (EHJ) moved to the second place with a 2012 impact factor of 14.097, directly behind Circulation (2012 impact factor of 15.202) and ahead of the Journal of the American College of Cardiology (JACC) with a 2012 impact factor of 14.086. Last year, the EHJ already ranked in the third place behind JACC (second) and Circulation (first). As a result, the EHJ Editor-in-Chief Thomas Lüscher (Zürich, Switzerland) and the EHJ

E. E. van der Wall $(\bowtie)$

Interuniversity Cardiology Institute of the Netherlands

(ICIN) - Netherlands Heart Institute (NHI), PO Box 19258,

3501 DG Utrecht, the Netherlands

e-mail: Ernst.van.der.wall@icin.knaw.nl
Editorial Board should be complimented. First place is within reach!

2) For the cardiovascular journals directed by Dutch Editors-in-Chief, the following remarkable results for the 2012 impact factors were observed:

a) The European Journal of Heart Failure (EJHF), fitting in the family of journals belonging to the European Society of Cardiology (ESC), received a 2012 impact factor of 5.247 versus a 2011 impact factor of 4.896, a rewarding increase. The Editorial Board of the EHJF is chaired by Dirk Jan van Veldhuisen (Groningen, the Netherlands) with Wiek van Gilst and Adriaan Voors as Deputy Editors.

b) For the journal Eurointervention, also part of the ESC journal family, with Patrick Serruys (Rotterdam, the Netherlands) as Editor-in-Chief, the 2012 impact factor was rather similar to the 2011 impact factor ( 3.285 in 2011 versus 3.173 in 2012)

c) The impact factor of the European Journal of Preventive Cardiology (another member of the ESC journal family), with Diederick Grobbee (Utrecht, the Netherlands) as Editor-in-Chief, moved from 2.634 in 2011 to 3.903 in 2012, a considerable increase!

d) The impact factor of the European Journal of Cardiovascular Nursing (also part of the ESC journal family), chaired by Tiny Jaarsma (currently residing in Norrköping, Sweden) as Editor-in-Chief, increased significantly from 1.711 in 2011 to 2.042 in 2012

e) Finally, the impact factor of the International Journal of Cardiovascular Imaging (CAIM), supervised by Hans Reiber (Leiden, the Netherlands) as Editor-inChief, moved from 2.285 in 2011 to 2.648 in 2012, also an obvious increase

The above-mentioned Editors-in-Chief should be congratulated on attaining a fine 2012 impact factor. This can be viewed as a major accomplishment, especially when 
recognising that there are currently more than 40,000 scientific journals worldwide.

Over time, impact factors have become the holy grail in the scientific journal domain [5]. Many authors wish to publish in the journals with the highest impact factors because this will increase their scientific image, their professional profile, and their academic career perspectives. As a result, every journal editor works hard to improve the journal's impact factor because it is viewed by publishers as an index of journal quality and success, determining the extent to which the journal is resourced by its sponsoring organisation or publisher [6-8]. However, there are many confounders that may influence the impact factor, at least challenging the scientific significance of an impact factor [9-12].

Nallomothu and Lüscher recently suggested that medical journals should move from the concept of 'impact' to 'influence' [12]. To that purpose, article-level metrics will probably play a more prominent role in the near future. As opposed to the impact factor, article-level metrics provide a major step forward in evaluating the performance of individual articles published in (cardiovascular) journals [13]. The Public Library of Science (PLoS) has been instrumental in developing several article-level metrics that integrate traditional approaches such as the impact factor which measures scientific impact with overall interest and readership. Pertinent questions are: 1) How often do others comment on articles and how do peers 'rank' these articles? 2) How many of the articles are being downloaded, and for how long? 3) How often are text, tables, and figures from the article 'cutand-pasted'? 4) How often are articles being selected by blogs, twitter, and lay media outlets? [12-15]. The concept of using article-level metrics, as a more objective and reliable way of measuring journal influence, may provide the true impact of a scientific journal.

In summary, the impact factor is still considered to be the nec plus ultra for authors, editors, publishers, and academic institutions. Although it is not very likely that a valid substitute for the impact factor will soon be implemented, the use of article-level metrics sounds noteworthy and hopeful. Until this approach has been accepted as a solid, reliable, and objective bibliometric index, we remain dependent on the impact factor for a journal quality index.

Open Access This article is distributed under the terms of the Creative Commons Attribution License which permits any use, distribution, and reproduction in any medium, provided the original author(s) and the source are credited.

\section{References}

1. Van der Wall. Increasing recognition of NHJ: a first-time impact factor of 1.4! Neth Heart J. 2010;18:399.

2. van der Wall EE, de Boer MJ, Doevendans PA, et al. Journal metrics for the Netherlands Heart Journal. Neth Heart J. 2011;19:159-61.

3. Opthof T, Wilde AA. Bibliometric data in clinical cardiology revisited. The case of 37 Dutch professors. Neth Heart J. 2011;19:246-55.

4. Opthof T. The impact factor of the Netherlands Heart Journal in 2013. Neth Heart J. 2013;21:319-21. doi :10.1007/s12471-0130443-6.

5. van der Wall EE. Journal impact factor: holy grail? Neth Heart J. 2012;20:385-6. doi:10.1007/s12471-012-0317-3.

6. Alfonso F, Timmis A, Pinto FJ, et al. Conflict of interest policies and disclosure requirements among European Society of Cardiology national cardiovascular journals. Neth Heart J. 2012;20:279-87.

7. van der Wall EE. Conflicts of interest: call for new editorial policies in European national journals. Neth Heart J. 2012;20:249-50. doi:10.1007/s12471-012-0287-5.

8. van der Wall EE. The NHJ 2012 in retrospect: which articles are cited most? Neth Heart J. 2012;20:481-2. doi:10.1007/s12471012-0336-0.

9. McAlister FA, Lawson FME, Good AH, et al. Evaluating research in cardiovascular medicine: citation counts are not sufficient. Circulation. 2011;123:1038-43.

10. Lüscher TF. Good publishing practice. Eur Heart J. 2012;33:55761. doi:10.1093/eurheartj/ehr506.

11. Opthof T. Inflation of impact factors by journal self-citation in cardiovascular science. Neth Heart J. 2013;21:163-5. doi:10. 1007/s12471-013-0384-0.

12. Nallamothu BK, Lüscher TF. Moving from impact to influence: measurement and the changing role of medical journals. Eur Heart J. 2012;33:2892-96.

13. Neylon C, Wu S. Article-level metrics and the evolution of scientific impact. PLoS Biol. 2009;7:e1000242.

14. Yarkoni T. Designing next-generation platforms for evaluating scientific output: what scientists can learn from the social web. SSRN eLibrary 2011.

15. Priem J, Piwowar HA, Hemminger BM. Altmetrics in the wild: using social media to explore scholarly impact. 2012. arXiv:1203.4745. 